Jurnal

Kardiologi Indonesia

J Kardiol Indones. 20 I3;34:126-32

ISSN $0126 / 3773$

\title{
Analgetic Sedation for Electrical Cardioversion in Emergency Room
}

\author{
Kurniawan Agung Yuwono
}

\begin{abstract}
General practitioner assigned in emergency room must have ability to do electrical cardioversion either in emergency, urgent or elective setting. Analgetic sedation is mandatory to avoid severe pain during electrical cardioversion. Limited number of anesthesiologist and emergency setting that need prompt electrical cardioversion warrant of selecting and using of analgetic sedation agents by doctor in emergency room. Characteristics of those agents must have strong analgesic effect and rapid onset and offset, minimize pain and anxiety and maximize amnesia with minimal adverse effect. This paper reviews some randomized control trial of those agents.
\end{abstract}

(J Kardiol Indones. 20 I 3;34: I 26-32)

Keywords: analgetic, sedation, cardioversion. 


\title{
Sedasi Analgesi Untuk Kardioversi Elektrik Di IGD
}

\author{
Kurniawan Agung Yuwono
}

\begin{abstract}
Seorang dokter IGD dituntut untuk mampu melakukan kardioversi elektrik, baik untuk kasus emergensi, urgensi maupun elektif di IGD. Kardioversi elektrik merupakan tindakan yang menimbulkan rasa nyeri pada pasien, sehingga dibutuhkan sedasi dan analgesi. Karena terbatasnya jumlah dokter anesthesia, maka dokter IGD diharapkan mampu melakukan sedasi dan analgesi procedural di IGD. Oleh karenanya dokter IGD harus mampu memilih agen anesthesia yang tepat. Agen anesthesia yang diperlukan untuk sedasi dan analgesi prosedur kardioversi elektrik harus mampu memberikan level sedasi yang adekuat dengan waktu induksi dan rekoveri yang pendek, meminimalkan nyeri dan ansietas, memaksimalkan amnesia, dan memiliki potensi efek samping yang minimal. Namun tidak ada agen anesthesia yang memenuhi semua kualifikasi tersebut. Tinjauan kepustakaan ini bertujuan merangkum bukti-bukti dari kumpulan Uji klinis kontrol teracak mengenai pemilihan agen anestesi untuk kardioversi elektrik di UGD.
\end{abstract}

(J Kardiol Indones. 2013;34:126-32)

Kata Kunci: IGD - analgesi, sedasi, kardioversi.

\section{Pendahuluan}

$\mathrm{P}$ enggunaan alat kardioversi harus dikuasai oleh dokter IGD, karena banyaknya kasus di IGD yang membutuhkan kardioversi. Menurut Panduan CPR\&ECC (cardiopulmonary resuscitation and emergency cardiovascular care) dari AHA 2010, kardioversi elektrik tersinkronisasi direkomendasikan untuk takikardia supraventrikular yang disebabkan oleh re-entrant, fibrillasi atrial, flutter atrial, dan takikardi atrial ${ }^{1}$. Kardioversi tersinkronisasi juga direkomendasikan untuk menangani V'T monomorfik dengan denyut ${ }^{1}$. Menurut panduan ACLS 2010, Bila pasien takikardia

\section{Alamat Korespondensi:}

Dr. Kurniawan Agung Yuwono, Tegalgondo RTO I/RWO I Wonosari, Klaten, Jawa Tengah, 57473, E-mail: dr.agungyuwono@gmail. com dalam keadaan tidak stabil dengan tanda-tanda dan gejala berat terkait dengan aritmia yang dicurigai (yakni: perubahan status mental akut, ketidaknyamanan di dada akibat kondisi iskemik, gagal jantung akut, hipotensi, atau tanda -tanda dari syok), kardioversi segera harus dilakukan (dengan sedasi sebelumnya pada pasien yang sadar)(kelas I, LOE: B) ${ }^{2}$.

Sedasi dan analgesi procedural merupakan tindakan yang harus dikuasai dan dilakukan sebelum dilakukan kardioversi pada pasien aritmia yang masih sadar. Di IGD, sedasi dan analgesi sering kali harus dilakukan oleh dokter IGD yang notabene bukan seorang ahli anesthesi, dikarenakan keterbatasan jumlah dokter ahli anestesi. Sehingga diperlukan pengetahuan mengenai pemilihan agen anesthesia yang akan digunakan. Selain itu manajemen jalan nafas dan monitoring tanda vital merupakan keharusan dalam prosedur sedasi dan analgesi. Panduan mengenai sedasi dan analgesi untuk Non-anesthesiologist 
dapat diperoleh dari oleh ASA (American Society of Anestehsiology) 3 dan ACEP (American College of Emergency Physicians) ${ }^{4}$.

\section{Metode}

Artikel dicari lewat situs PubMed dengan kata kunci "sedation" AND "anesthesia" AND "cardioversion". Jurnal harus berupa Uji klinis control teracak (randomized control clinical trial) selanjutnya disebut RCT, mengenai perbandingan penggunaan agen anestesi untuk kardioversi elektrik tersinkronisasi.

\section{Hasil}

Didapatkan 7 artikel RCT yang relevan. Perbandingan masing-masing jurnal RCT dibuat dalam bentuk tabel. Berikut data-data dari RCT tersebut.

\section{Pembahasan}

Dari beberapa RCT mengenai sedasi dan analgesi untuk kardioversi, dapat disimpulkan bahwa rentang level sedasi dapat dgunakan mulai dari sedasi moderate sampai anesthesia general. Agen sedasi yang digunakan pada penelitian tersebut berkisar pada turunan benzodiazepine (midazolam dan diazepam), thiopentone, propofol, dan etomidate.

\section{Pemilihan Agen Anesthesi}

Pada analisis kumpulan RCT di atas, Midazolam, diazepam, etomidat, propofol dan thiopentone memiliki waktu induksi yang hampir sama, sedangkan turunan benzodiazepin memiliki waktu rekoveri yang lebih lama. Turunan benzodiazepine (midazolam dan diazepam), propofol dan thiopentone memiliki efek samping penurunan tekanan darah, sedangkan etomidate tidak terlalu mempengaruhi stabilitas hemodinamik, namun memiliki efek samping myoclonus. Lebih dari $30 \%$ pasien yang menggunakan agen anesthesia turunan benzodiazepin mengalam efek unsteadiness, tiredness, lightheadedness 24 jam paska prosedur, $7 \%-20 \%$ mengalami hipotensi. Dari data di atas, thiopentone, propofol dan etomidate lebih dipilih dibandingkan turunan benzodiazepine.
Studi - studi prospektif observasional mengenai penggunaan propofol di UGD untuk sedasi dan analgesi prosedural menunjukkan efektivitas yang tinggi dan efek samping yang rendah ${ }^{12,13}$. Sebuah studi retrospektif observasional pada pasien AF persisten yang akan menjalani kardioversi elektrik elektif menunjukkan bahwa propofol lebih aman dibandingkan sodium thiopental ${ }^{14}$. Etomidate memiliki keunggulan berupa tidak mengganggu stabilitas hemodinamik bila dibandingkan dengan propofol, namun etomidate memiliki efek samping berupa myoclonus. Sebuah RCT tersamar-ganda mengenai premedikasi midazolam iv dosis rendah $(0,015 \mathrm{mg} / \mathrm{kg}) 90$ detik sebelum induksi dengan etomidate dapat menurunkan kejadian myoclonus dibandingkan placebo $(10 \%$ vs $50 \%$, $\mathrm{p}=0,006)^{15}$.

Menurut guideline ASA mengenai sedasi dan analgesi oleh non-anesthesiologist, agen anesthesia propofol dan ketamine dapat memberikan efek sedasi moderat yang memuaskan, dan methohexital untuk sedasi dalam ${ }^{3}$. Menurut panduan dari ACEP, obat yang dapat digunakan secara aman di UGD untuk sedasi dan analgesi procedural adalah ketamine (level rekomendasi A), Propofol (level rekomendasi B), dan etomidate (level rekomendasi C) ${ }^{4}$.

\section{Level Sedasi dan Dosis}

Harrison\&Mayet menyatakan bahwa standar sedasi untuk kardioversi adalah anesthesia general atau sedasi dalam dengan menggunakan agen anesthesia kerja singkat dengan profil rekoveri yang cepat ${ }^{16}$. Namun sampai saat ini belum ada penelitian yang membandingkan mengenai berapa dalam level sedasi yang ideal untuk kardioversi elektrik, sehingga belum ada patokan mengenai dosis yang dianjurkan. Menurut panduan ASA, agen sedasi/analgesi intravena harus diberikan mulai dari dosis kecil, meningkat bertahap, dan dititrasi sampai titik akhir analgesi dan sedasi yang diinginkan ${ }^{3}$. Dosis propofol yang umum digunakan di UGD adalah bolus inisial $1,0 \mathrm{mg} / \mathrm{kg}$ diikuti $0,5 \mathrm{mg} /$ $\mathrm{kg}$ tiap 3 menit bila dibutuhkan untuk mencapai atau mempertahankan sedasi (dosis dewasa dan anak sama) $)^{9,17}$.

Monitoring dan perawatan pasien dengan sedasi moderat sama dengan perawatan pasien dengan sedasi dalam ${ }^{3}$. Monitoring meliputi level kesadaran dan ventilasi paru (dengan observasi dan auskultasi), oksigenasi (dengan pulse oxymetry, capnography), hemodinamik 
Setianto BY dkk: Iskemia tungkai akut

Table penelitian anesthesia dan analgesia procedural

\begin{tabular}{|c|c|c|c|c|c|c|c|}
\hline \multirow[t]{2}{*}{ No } & \multirow{2}{*}{$\begin{array}{c}\text { Penulis, tahun } \\
\text { dan Negara }\end{array}$} & \multirow{2}{*}{$\begin{array}{c}\text { Grup yang } \\
\text { dibandingkan }\end{array}$} & \multirow{2}{*}{$\begin{array}{c}\text { level sedasi dan } \\
\text { dosis }\end{array}$} & \multicolumn{3}{|c|}{ Luaran } & \multirow[t]{2}{*}{ kesimpulan } \\
\hline & & & & Waktu induksi & Waktu rekoveri & Komplikasi & \\
\hline 1. & $\begin{array}{l}\text { Kalogridaki et } \\
\mathrm{al}^{5}, 2011 \text {, Hel- } \\
\text { lenic Journal } \\
\text { of Cardiology, } \\
\text { Yunani }\end{array}$ & $\begin{array}{l}\text { RCT pada } \\
46 \text { pasien AF } \\
\text { persisten : Grup } \\
\text { P: Propofol + } \\
\text { fentanil }(\mathrm{N}=25) \text { vs } \\
\text { Grup E: etomidat } \\
\text { + fentanil }(\mathrm{N}=21)\end{array}$ & $\begin{array}{l}\text { Anesthesia general } \\
\text { (tidak berespon ter- } \\
\text { hadap perintah, dan } \\
\text { hilang reflek bulu } \\
\text { mata) . fentanil } \\
50 \mu \mathrm{g} \text { i.v., propo- } \\
\text { fol 0,5mg/kg i.v., } \\
\text { etomidate } 0,1 \mathrm{mg} / \\
\text { kg i.v., pengulan- } \\
\text { gan dosis } 20 \mathrm{mg} \\
\text { propofol, atau } 4 \\
\text { mg etomidate. }\end{array}$ & $\begin{array}{l}\text { Waktu dari } \\
\text { injeksi agen } \\
\text { sampai hilang } \\
\text { kesadaran } \\
\text { Grup P vs } \mathrm{E}= \\
118 \mathrm{dtk} \pm 95 \\
\text { vs } 49 \mathrm{dtk} \pm 47 \\
\mathrm{p}=0,003 .\end{array}$ & $\begin{array}{l}\text { waktu untuk } \\
\text { membuka } \\
\text { mata ( } \mathrm{P} \text { vs } \\
\mathrm{E}=204 \pm 117 \\
\mathrm{vs} 195 \pm 152, \\
\mathrm{p}=.82) \\
\text { waktu untuk } \\
\text { mampu } \\
\text { menjawab per- } \\
\text { tanyaan seder- } \\
\text { hana ( } \mathrm{p} \text { vs } \mathrm{E}= \\
269 \mathrm{dtk} \pm 112 \text { vs } \\
251 \mathrm{dtk} \pm 167, \\
\mathrm{p}=0,67),\end{array}$ & $\begin{array}{l}\text { komplikasi grup } P \\
\text { vs E tidak berbeda } \\
\text { bermakna seperti } \\
\text { penurunan sBP } \\
\geq 20 \%(5 / 25 \text { vs } \\
0 / 21) \text {, apnoea } \\
(7 / 25 \text { vs } 10 / 21) \text {, } \\
\text { kebutuhan ventila- } \\
\text { si manual }(7 / 25 \text { vs } \\
9 / 21) \text {, nyeri injeksi } \\
\text { intra vena }(7 / 25 \text { vs } \\
4 / 21), \text { recall nyeri } \\
(3 / 25 \text { vs } 1 / 21), \\
\text { kecuali myo- } \\
\text { clonus }(0 / 25 \text { vs } \\
11 / 21, p=0,0004) \text {. } \\
\text { penurunan sBP } \\
\text { baseline- paska } \\
\text { induksi grup P } \\
=15,2 \mathrm{mmHg}, \\
\text { p=0,001. }\end{array}$ & $\begin{array}{l}\text { perhitungan } \\
\text { kekuatan studi } \\
\text { tidak dilakukan. } \\
\text { Tidak dijelaskan } \\
\text { metode "blind- } \\
\text { ing". }\end{array}$ \\
\hline 2. & $\begin{array}{l}\text { Siedy et } \mathrm{al}^{6} \text {, } \\
\text { 2010, Kardio- } \\
\text { logia Polska, } \\
\text { Polandia, }\end{array}$ & $\begin{array}{l}100 \text { pasien aritmia } \\
\text { atrial stabil yang } \\
\text { belum pernah di } \\
\text { ECV sebelumnya: } \\
\text { grup I : Propofol } \\
(\mathrm{N}=50) \text {; } \\
\text { grup II : Fenta- } \\
\text { nyl + etomidate } \\
(\mathrm{N}=50) \text {. }\end{array}$ & $\begin{array}{l}\text { Anestesi general. } \\
\text { grup I : Propofol } \\
\text { bolus } 1 \mathrm{mg} / \mathrm{kg} \text {, dii- } \\
\text { kuti } 0,2 \mathrm{mg} / \mathrm{kg} / \mathrm{kali} \\
\text { grup II : Fentanyl } \\
\text { i.v. }(1 \mu \mathrm{g} / \mathrm{kg} \text { dosis } \\
\text { tunggal }+ \text { etomi- } \\
\text { date bolus o, } 15 \mathrm{mg} / \\
\mathrm{kg} \text { diikuti } 0,03 \mathrm{mg} / \\
\mathrm{kg} / \mathrm{kali} \text {. }\end{array}$ & $\begin{array}{l}\text { Grup I vs II: } \\
10,7 \mathrm{mnt} \pm 3,0 \\
\text { vs } 10,1 \mathrm{mnt} \pm \\
3,9, \mathrm{p}=\mathrm{NS} ;\end{array}$ & $\begin{array}{l}\text { Waktu dari } \\
\text { membuka mata } \\
\text { oleh perin- } \\
\text { tah verbal } \\
\text { s.d. waktu } \\
\text { mencapai skor } \\
\text { Aldrette } 10= \\
\text { grup I vs II: } \\
4,7 \pm 2,2 \text { mnt vs } \\
6,7 \pm 4,0 \text { mnt, } \\
\text { p }<0,01 \text {. }\end{array}$ & $\begin{array}{l}\text { Grup I vs grup II: } \\
\text { Nyeri ketika in- } \\
\text { jeksi } 8 \% \text { vs } 22 \% \text {, } \\
\text { p<0,05; tremor } \\
\text { selama anest- } \\
\text { esi : } 2 \% \text { vs } 14 \% \text {, } \\
\text { p<0,05; mual } \\
\text { muntah setelah } \\
\text { bangun : } 1 \% \text { vs } \\
8 \%, p<0,05 ; \\
\text { Apnea : } 6 \% \text { vs } 4 \% \text {, } \\
\text { p=NS. } \\
\text { sBP sebelum } \\
\text { dilakukan ECV: } \\
116,5 \pm 15,1 \text { vs } \\
128,4 \pm 17,8, \\
\text { p }<0,01,\end{array}$ & $\begin{array}{l}\text { perhitungan } \\
\text { kekuatan studi } \\
\text { tidak dilakukan. } \\
\text { Tidak dijelaskan } \\
\text { metode "blind- } \\
\text { ing". }\end{array}$ \\
\hline
\end{tabular}


(Lanjutan)

\begin{tabular}{|c|c|c|c|c|c|c|c|}
\hline \multirow[t]{2}{*}{ No } & \multirow{2}{*}{$\begin{array}{l}\text { Penulis, tahun } \\
\text { dan Negara }\end{array}$} & \multirow{2}{*}{$\begin{array}{c}\text { Grup yang diband- } \\
\text { ingkan }\end{array}$} & \multirow[t]{2}{*}{ level sedasi dan dosis } & \multicolumn{3}{|c|}{ Luaran } & \multirow[t]{2}{*}{ kesimpulan } \\
\hline & & & & Waktu induksi & Waktu rekoveri & Komplikasi & \\
\hline 3. & $\begin{array}{l}\text { Parlak et al } \\
\text { 2006, Academ- } \\
\text { ic Emergency } \\
\text { Medicine, } \\
\text { Turki }\end{array}$ & $\begin{array}{l}\text { RCT } 70 \text { pasien } \\
\text { AF menjalani ECV } \\
\text { elektif: Grup 1: } \\
\text { Midazolam usia < } \\
65 \text { thn }(\mathrm{N}=12) \text { dan } \\
\text { grup } 2: \text { propofol } \\
<65 \text { thn }(\mathrm{N}=11) \text {, } \\
\text { Grup } 3: \text { midazo- } \\
\text { lam usia } \geq 65 \text { thn } \\
(\mathrm{N}=25) \text {; grup } 4: \\
\text { propofol usia } \geq 65 \\
\text { thn }(\mathrm{N}=22)\end{array}$ & $\begin{array}{l}\text { Sedasi dalam } \\
\text { (RSS } 5=\text { berespon } \\
\text { lambat terhadap } \\
\text { nyeri). Fentanil } \\
1 \mu \mathrm{g} / \mathrm{kg} \text { untuk } \\
\text { grup } 3 \& 4,0,5 \mu \mathrm{g} / \\
\mathrm{kg} \text { untuk grup } \\
1 \& 2 \text {, midazolam } \\
2 \mathrm{mg} \text { dilanjutkan } 1 \\
\text { mg/2mnt. Propofol- } \\
20 \mathrm{mg} \text {, dilanjutkan } \\
20 \mathrm{mg} / 2 \mathrm{mnt} \text {. }\end{array}$ & $\begin{array}{l}\text { grup } 1=8,08 \\
\text { mnt, } \\
\text { grup } 2=8,36 \\
\text { mnt; } \\
\text { grup } 3=7,12 \\
\text { mnt; } \\
\text { grup } 4=7,86 \\
\text { mnt; } \\
\text { p=0,22 }\end{array}$ & $\begin{array}{l}\text { waktu pemuli- } \\
\text { han s.d. pasien } \\
\text { kooperatif } \\
\text { grup1=40,33 } \\
\text { mnt; } \\
\text { grup2=18,18 } \\
\text { mnt; } \\
\text { grup3=54,20 } \\
\text { mnt; } \\
\text { grup4=18,22 } \\
\text { mnt; } p<.001 \text { ) }\end{array}$ & $\begin{array}{l}\text { efek samping } \\
\text { seperti apnea, } \\
\text { ketidakpuasan } \\
\text { pasien, mengingat } \\
\text { kejadian, tidak } \\
\text { beda bermakna } \\
\text { kecuali desaturasi } \\
\text { (grup } 1=18,2 \% ; \\
\text { grup } 2=9,1 \% ; \\
\text { grup } 3=64,7 \% ; \\
\text { grup } 4=19 \%, p= \\
.001)\end{array}$ & $\begin{array}{l}\text { Jumlah sampel } \\
\text { kecil, perhitun- } \\
\text { gan kekuatan } \\
\text { studi tidak } \\
\text { dilakukan. Me- } \\
\text { tode "blinding" } \\
\text { tidak dijelaskan. }\end{array}$ \\
\hline 4. & $\begin{array}{l}\text { Mitchell et } \\
\mathrm{al}^{8}, 2003, \mathrm{Eu}- \\
\text { ropace, UK }\end{array}$ & $\begin{array}{l}\text { RCT single- } \\
\text { blinded } 141 \text { pasien } \\
\text { aritmia atrial men- } \\
\text { jalani ECV elektif: } \\
\text { grup I midazolam } \\
(\mathrm{N}=71) \text {, dan } \\
\text { grup II diazepam } \\
(\mathrm{N}=70) \text {. }\end{array}$ & $\begin{array}{l}\text { Sedasi moderat. } \\
\text { Dosis midazolam } \\
5 \mathrm{mg} \text { bolus dilan- } \\
\text { jutkan } 1-2 \mathrm{mg} / \mathrm{mnt} \text {, } \\
\text { diazepam } 5-10 \mathrm{mg} \\
\text { bolus diikuti } \\
5-10 \mathrm{mg} / \mathrm{mnt}\end{array}$ & $\begin{array}{l}\text { Grup I : } \\
5,0 \mathrm{mnt} \pm 3,4 \\
\text { vs grup II: } \\
6,5 \mathrm{mnt} \pm 3,4 ; \\
\mathrm{p}=0,0016\end{array}$ & $\begin{array}{l}\text { Grup I : } \\
77 \mathrm{mnt} \pm 46 \\
\text { vs grup II : } \\
39 \mathrm{mnt} \pm 24 \text {; } \\
\mathrm{p}<0,0001 \text {. }\end{array}$ & $\begin{array}{l}\text { Grup I : Hipotensi } \\
20 \%, \text { desatu- } \\
\text { rasi oksigen 3\% vs } \\
\text { grup II : hipo- } \\
\text { tensi } 7 \% \text {, perlu } \\
\text { analgesi tambahan } \\
\text { 6\%, p=0,14. Efek } \\
\text { dalam } 24 \text { jam } \\
\text { (unsteadiness, } \\
\text { tiredness, light- } \\
\text { headedness) 32\% } \\
\text { vs 34\%, p=NS }\end{array}$ & $\begin{array}{l}\text { obat tidak } \\
\text { tersamar untuk } \\
\text { operator. perhi- } \\
\text { tungan kekua- } \\
\text { tan studi tidak } \\
\text { dilakukan. }\end{array}$ \\
\hline 5. & $\begin{array}{l}\text { Coll-Vinent et } \\
\mathrm{al}^{9}, 2003 \text {, Ann } \\
\text { Emerg Med, } \\
\text { Spanyol. }\end{array}$ & $\begin{array}{l}\text { RCT pada } 23 \\
\text { pasien dengan he- } \\
\text { modinamik stabil } \\
\text { yang menjalani } \\
\text { ECV elektif di } \\
\text { UGD, } \\
\text { Menerima: etomi- } \\
\text { date }(\mathrm{E})(\mathrm{N}=9) \text {, } \\
\text { propofol }(\mathrm{P}) \\
(\mathrm{N}=9) \text {, midazolam } \\
(\mathrm{M})(\mathrm{N}=8) \text {, atau } \\
\text { midazolam diikuti } \\
\text { flumazenil }(\mathrm{M}+\mathrm{F}) \\
(\mathrm{N}=6)\end{array}$ & $\begin{array}{l}\text { Sedasi dalam. } \\
\text { etomidate }(0,2 \mathrm{mg} / \\
\mathrm{kg} \text { diikuti } 0,05 \mathrm{mg} / \\
\mathrm{kg}) \text {, propofol } \\
(1,5 \mathrm{mg} / \mathrm{kg} \text { diikuti } \\
0,5 \mathrm{mg} / \mathrm{kg}), \mathrm{mida}- \\
\text { zolam }(0,2 \mathrm{mg} / \mathrm{kg} \\
\text { diikuti } 0,05 \mathrm{mg} / \\
\mathrm{kg}) \text {, flumazenil } \\
\text { (bolus } 0,5 \mathrm{mg} \text { diikuti } \\
0,5 \mathrm{mg} \text { iv selama } 1 \\
\text { jam) }\end{array}$ & $\begin{array}{l}\text { Waktu induksi } \\
\text { (detik) E: } 90 \text {, } \\
\text { P: } 50, \mathrm{M}: 120 \text {, } \\
\mathrm{M}+\mathrm{F}: 112, \\
\mathrm{p}=0,28\end{array}$ & $\begin{array}{l}\text { Waktu induksi } \\
\text { s.d. membuka } \\
\text { mata spontan } \\
\text { (mnt) E:9,5; } \\
\text { P:8; M:21; } \\
\text { M+F:3; } \\
\text { p=0,038 } \\
\text { Waktu } \\
\text { rekuperasi } \\
\text { E: } 14, P: 10, \\
\text { M: } 45, M+F: 5 ; \\
p=0,025\end{array}$ & $\begin{array}{l}\text { Apneu E:2/9, } \\
\text { P:2/9, M:3/8, } \\
\text { M+F:1/6. } \\
\text { Myoclonus: E:4/9. } \\
\text { Desaturasi E:1/9, } \\
\text { P:4/9, M:0/8, } \\
\text { M+F:2/6. } \\
\text { Penurunan sBP } \\
\text { tidak bermakna } \\
\text { secara klinis utk } \\
\text { semua grup. }\end{array}$ & $\begin{array}{l}\text { Jumlah sampel } \\
\text { kecil, perhitun- } \\
\text { gan kekuatan } \\
\text { studi tidak } \\
\text { dilakukan. }\end{array}$ \\
\hline
\end{tabular}


Setianto BY dkk: Iskemia tungkai akut

\begin{tabular}{|c|c|c|c|c|c|c|c|}
\hline \multirow[t]{2}{*}{ No } & \multirow{2}{*}{$\begin{array}{l}\text { Penulis, tahun } \\
\text { dan Negara }\end{array}$} & \multirow{2}{*}{$\begin{array}{c}\text { Grup yang diband- } \\
\text { ingkan }\end{array}$} & \multirow{2}{*}{$\begin{array}{l}\text { level sedasi dan } \\
\text { dosis }\end{array}$} & \multicolumn{3}{|c|}{ Luaran } & \multirow[t]{2}{*}{ Kesimpulan } \\
\hline & & & & Waktu induksi & Waktu rekoveri & Komplikasi & \\
\hline 6 & $\begin{array}{l}\text { Hullander et } \\
\mathrm{al}^{10}, 1993, \\
\text { Anesth Analg, } \\
\text { Amerika Serikat }\end{array}$ & $\begin{array}{l}40 \text { pasien ECV } \\
\text { elektif, dibagi : } \\
\text { Grup propofol } \\
\text { infus dosis rendah } \\
(\mathrm{P})(\mathrm{N}=20) \text {, Grup } \\
\text { etomidat }(\mathrm{E}) \\
(\mathrm{N}=20) \text {. kedua } \\
\text { grup diberikan } \\
\text { lidocaine } 0,5 \mathrm{mg} / \\
\text { kg sblm induksi } \\
\text { anesthesia untuk } \\
\text { menghilangkan } \\
\text { nyeri. }\end{array}$ & \begin{tabular}{|l|} 
Sedasi dalam. $P$ \\
diberikan dalam \\
infus $50 \mathrm{mg} / \mathrm{mnt}, \&$ \\
E dalam $8 \mathrm{mg} / \mathrm{mnt}$, \\
sampai pasien tidak \\
berespon terhadap \\
perintah verbal.
\end{tabular} & $\begin{array}{l}\text { Grup P vs } \mathrm{E}= \\
2,2 \mathrm{mnt} \pm 0,7 \\
\text { vs } 2,3 \mathrm{mnt} \\
\pm 0,8 ; \mathrm{p}=0,57\end{array}$ & $\begin{array}{l}\text { Waktu pengh- } \\
\text { entian obat } \\
\text { sampai pasien } \\
\text { bangun } P=4,5 \\
\text { mnt } \pm 2,0 ; \\
E=4,6 \mathrm{mnt} \\
\pm 2,1 ; \mathrm{p}=0,87\end{array}$ & $\begin{array}{l}\text { Grup } P \text { vs } \mathrm{E}= \\
\text { nyeri pada injeksi } \\
0 / 20 \text { vs } 0 / 20 \text {, re- } \\
\text { call/ mimpi buruk } \\
0 / 20 \text { vs } 0 / 20 \text {, } \\
\text { mual } 0 / 20 \text { vs } \\
0 / 20 \text {, apnea } 2 / 20 \\
\text { vs } 1 / 20, \mathrm{p}=\mathrm{NS} \text {, } \\
\text { myoclonus } \mathrm{P}=0 \text {; } \\
\mathrm{E}=9 \text {; } \mathrm{p}<.00005 \text {. } \\
\text { status kardiovasku- } \\
\text { lar kedua grup } \\
\text { dalam level yang } \\
\text { dapat diterima } \\
\text { secara klinis. }\end{array}$ & $\begin{array}{l}\text { Jumlah sampel } \\
\text { kecil, perhitun- } \\
\text { gan kekuatan } \\
\text { studi tidak } \\
\text { dilakukan. } \\
\text { Tidak dijelaskan } \\
\text { metode "blind- } \\
\text { ing". }\end{array}$ \\
\hline 7. & $\begin{array}{l}\text { Valtonen et } \\
\mathrm{al}^{11}, 1988, \mathrm{Ca}- \\
\text { nadian Journal } \\
\text { of Anaesthesia, } \\
\text { Finlandia. }\end{array}$ & $\begin{array}{l}\text { RCT } 30 \text { pasien } \\
\text { AF yang menjalani } \\
\text { ECV elektif: } \\
\text { grup P: propofol } \\
(\mathrm{N}=15) \text {, } \\
\text { grup } \mathrm{T} \text { : Thiopen- } \\
\text { tone }(\mathrm{N}=15) \text {. }\end{array}$ & \begin{tabular}{|l} 
Level sedasi : \\
sedasi dalam. Dosis \\
thiopentone $5 \mathrm{mg} /$ \\
$\mathrm{kg}$ iv, dosis propofol \\
$2,5 \mathrm{mg} / \mathrm{kg}$ iv, pasien \\
diamati sampai \\
tidak berespon \\
terhadap rangsang \\
verbal.
\end{tabular} & $\begin{array}{l}\text { Grup P vs grup } \\
T=72,0 \mathrm{~s} \pm 20 \mathrm{~s} \\
\text { vs } 60,3 \mathrm{~s} \pm 13 \mathrm{~s}\end{array}$ & $\begin{array}{l}\text { Waktu dari } \\
\text { akhir prosedur } \\
\text { sampai pasien } \\
\text { berorientasi : } \\
\text { grup P vs Grup } \\
\mathrm{T}=7,7 \pm 2,9 \\
\text { mnt vs } 6,5 \pm 4,4 \\
\text { mnt }\end{array}$ & $\begin{array}{l}\text { Penurunan MAP } \\
\text { setelah induksi } \\
\text { anesthesia pada } \\
\text { kedua grup tidak } \\
\text { berbeda ber- } \\
\text { makna, nyeri pada } \\
\text { injeksi grup P vs } \\
\text { grup } \mathrm{T}=2 / 15 \text { vs } \\
0 / 15\end{array}$ & $\begin{array}{l}\text { Jumlah sampel } \\
\text { kecil, perhitun- } \\
\text { gan kekuatan } \\
\text { studi tidak } \\
\text { dilakukan, } \\
\text { sebagian data } \\
\text { berbentuk grafik } \\
\text { sehingga sulit } \\
\text { bila dimasuk- } \\
\text { kan dalam tabel. } \\
\text { Tidak dijelaskan } \\
\text { metode "blind- } \\
\text { ing". }\end{array}$ \\
\hline
\end{tabular}

Ket: AF : atrial fibrillasi, dtk : detik, ECV : electrical cardioversion, mnt : menit, RCT : randomized control clinical trial.

(ekg, tekanan darah, dan denyut jantung). Selain itu direkomendasikan terdapat satu petugas kesehatan yang bertugas khusus memonitor pasien ${ }^{3,4}$.

\section{Keterbatasan}

Studi - studi RCT yang dibahas pada tinjauan kepustakaan ini hanya meneliti perbandingan agen anesthesia untuk kardioversi elektrik elektif saja. Padahal penggunaan kardioversi elektrik tersinkronisasi lebih ditekankan untuk aritmia tidak stabil sebagaimana disebutkan dalam panduan ACLS 2010, dengan kelas rekomendasi I, dan level bukti: B. Pasien aritmia tidak stabil lebih rentan terhadap efek instabilitas kardiorespirasi akibat agen anesthesia dibandingkan pasien aritmia stabil.

Selain itu, jurnal satu dengan yang lain membandingkan agen anestesi yang berbeda dan dengan tingkat kedalaman anestesi yang tidak sama sehingga sulit diambil kesimpulan yang konklusif mengenai kelebihan dan kekurangan masing-masing agen anestesi dan dosis yang dianjurkan untuk sedasi dan analgesi pada kardioversi elektrik. 


\section{Kesimpulan}

Kardioversi elektrik merupakan salah satu tindakan procedural yang esensial di UGD yang menimbulkan rasa nyeri, sehingga diperlukan tindakan sedasi dan analgesi prosedural pada pasien sadar. Propofol dan etomidate merupakan agen yang dipilih untuk sedasi dan analgesi kardioversi elektrik di UGD, karena waktu induksi dan rekoveri yang singkat dan lebih aman. Diazepam dan midazolam diprioritaskan sebagai lini kedua, karena waktu rekoveri lebih lama dan efek samping paska sedasi yang tinggi. Level sedasi yang digunakan untuk kardioversi elektrik bervariasi dari sedasi moderate sampai anesthesia general, sehingga patokan dosis belum dapat ditentukan, tergantung level sedasi yang diinginkan. Panduan ASA mengenai sedasi dan analgesi menyarankan untuk agen anesthesia intravena harus mulai dari dosis kecil dinaikkan secara bertahap dan dititrasi sampai level sedasi yang diinginkan.

\section{Daftar Pustaka}

1. Link M S, Atkins D L, Passman R S, Halperin H R, Samson R A. et al. Part 6: Electrical Therapies: Automated External Defibrillators, Defibrillation, Cardioversion, and Pacing - 2010 American Heart Association Guidelines for Cardiopulmonary Resuscitation and Emergency Cardiovascular Care. Circulation 2010;122;S706-S719

2. Neumar R W, Otto C W, Link M S, Kronick S L, Shuster M, et al. Part 8: Adult Advanced Cardiovascular Life Support: 2010 American Heart Association Guidelines for Cardiopulmonary Resuscitation and Emergency Cardiovascular Care. Circulation 2010;122;S729-S767

3. American Society of Anesthesiologists. Practice Guidelines for Sedation and Analgesia by Non-Anesthesiologists An Updated Report by the American Society of Anesthesiologists Task Force on Sedation and Analgesia by Non-Anesthesiologists. Anesthesiology 2002; 96:1004-17.

4. The American College of Emergency Physicians Clinical Policies Subcommittee (Writing Committee) on Procedural Sedation and Analgesia : Godwin S A, Caro D A, Wolf S J, Jagoda A S, Charles R, Marett B E, Moore J. Clinical Policy: Procedural Sedation and Analgesia in the Emergency Department. Ann Emerg Med. 2005;45:177-196.
5. Kalogridaki M, Souvatzis X, Mavrakis H E, Kanoupakis E M, Panteli A, Kasotaki S, Vardas P, Askitopoulou H. Anaesthesia for Cardioversion: A Prospective Randomised Comparison of Propofol and Etomidate Combined with Fentanyl. Hellenic J Cardiol 2011; 52: 483-488.

6. Siedy J., Knapik P., Saucha W., Gross M. Comparison of propofol and etomidate anaesthesia for elective electrical cardioversion. Kardiologia Polska 2010; 68, 11: 1249 - 1255.

7. Parlak M, Parlak I, Erdur B, Ergin A, Sagiroglu E. Age Effect on Efficacy and Side Effects of Two Sedation and Analgesia Protocols on Patients Going through Cardioversion: A Randomized Clinical Trial. ACADEMIC EMERGENCY MEDICINE 2006; 13:493-499.

8. Mitchell A R J, Chalil S, Boodhoo L, Bordoli G, Patel N, Sulke N. Diazepam or Midazolam for External DC cardioversion (the DORM Study). Europace 2003; 5: 391-395.

9. Coll-Vinent B, Sala X, Fernandez C, Bragulat E, et al. Sedation for Cardioversion in the Emergency Department: Analysis of Effectiveness in Four Protocols. Ann Emerg Med. 2003;42:767772.

10. Hullander R M, Leivers D, Wingler K. A Comparison of Propofol and Etomidate for Cardioversion. Anesth Analg 1993; 77: 690-4.

11. Valtonen M, Kanto J, Klossner J. Anaesthesia for cardioversion: A comparison of propofol and thiopentone. Can J Anaesth 1988; 35, $5: 479-83$.

12. Frazee B W, Park R S, Lowery D, Baire M. Propofol for deep procedural sedation in the ED. American Journal of Emergency Medicine (2005) 23, 190-195

13. Zed P J, Abu-Laban R B, Chan W W Y, Harrison D W. Efficacy, safety and patient satisfaction of propofol for procedural sedation and analgesia in the emergency department: a prospective study. Can J Emerg Med 2007;9(6):421-7

14. Serpytis P, Jurkuvenas V, Skromovas V, Serpytis R. Propofol is a safer anaesthetic agent than sodium thiopental during cardioversion in patients with depressed left ventricular function. Seminars in Cardiovascular Medicine 2010; 16: 2

15. Huter L, Schreiber T, Gugel M, Schwarzkopf K. Low-Dose Intravenous Midazolam Reduces Etomidate-Induced Myoclonus: A Prospective, Randomized Study in Patients Undergoing Elective Cardioversion. Anesth Analg 2007;105:1298 -302.

16. Harrison S J, Mayet J. Cardioversion and the use of sedation. Heart 2004;90:1374-1376.

17. Miner J R, Burton J H. Clinical Practice Advisory: Emergency Department Procedural Sedation With Propofol. Ann Emerg Med. 2007;50:182-187. 